\title{
AMF O paradigma sapiencial do ius
}

\section{Fábio Cardoso Machado ${ }^{1}$}

Resumo: Este artigo investiga a compreensão pré-moderna do direito. O objetivo é demonstrar que antes da modernidade o direito era compreendido mais como um saber prático-prudencial do que como uma expressão do poder político. Para isso, explora-se as experiências jurídicas romana e medieval, através da revisão bibliográfica dos mais proeminentes historiadores do direito antigo. Conclui-se que a compreensão pré-moderna da juridicidade se contrapõe ao modelo político da lex, predominante a partir da modernidade.

Palavras-chave: Direito; Ius; saber jurídico; racionalidade prático-jurídica.

\section{The sapiential paradigm of ius}

Abstract: This article investigates the premodern understanding of law. The aim is to demonstrate that before modernity law was understood more as a practical-prudential wisdom than as an expression of political power. To this end, it explores the Roman and medieval legal experiences through the literature review of the most prominent historians of ancient law. It concludes that the premodern understanding of law contrasts with the political model of lex, which is prevalent in modernity.

Keywords: Law; Ius; legal knowledge; legal reasoning.

\section{El paradigma sapiencial del ius}

Resumen: Este artículo investiga la comprensión pre moderna del derecho. El objetivo es demostrar que antes de la modernidad el derecho se entendía más como un saber práctico-prudencial que como una expresión del poder político. Con este fin, explora las experiencias jurídicas romana y medieval. Concluye que la comprensión pre moderna del derecho contrasta con el modelo político de la lex, que prevalece en la modernidad.

Palabras clave: Derecho; Ius; saber jurídico; racionalidad práctico-jurídica.

\section{Introdução}

No princípio, o direito era a expressão de um saber. Não de um poder. De um saber prático-prudencial que se traduzia em regras e princípios e que, por ser um saber, desfrutava de uma autoridade muito própria. Este artigo é parte de um esforço de restauração dessa compreensão pré-moderna do direito. Para alcançar esse objetivo, explora as experiências jurídicas romana e medieval, através da revisão bibliográfica dos

\footnotetext{
${ }^{1}$ Doutor em Ciências Jurídico-Filosóficas pela Universidade de Coimbra. Mestre em Direito pela Universidade do Vale do Rio dos Sinos (UNISINOS). Professor da Escola de Direito da PUC/RS. Advogado.
} 
mais proeminentes historiadores do direito antigo. Conclui que aquela compreensão, correspondente ao paradigma sapiencial do ius, se contrapõe ao modelo político da lex, predominante a partir da modernidade.

\section{Fundamentação Teórica}

\subsection{A emergência histórica de um direito autônomo}

A longa história da formação do direito romano começa com a interpretatio pontifícia. Os pontífices eram os mais importantes depositários e intérpretes do acervo de conhecimentos da comunidade (SCHIAVONE, 2005, p. 62). Embora primitivamente a religião, a moralidade e o direito se encontrassem ainda fundidos num todo indiferenciado, sob os cuidados dos pontífices vai lentamente se desenvolvendo um saber especializado que assumirá os contornos de uma autêntica iurisprudentia, consistente numa interpretatio tendente a revelar um ius (non scriptum) involucrado nos mores maiorum (CRUZ, 1984, p. 172-173). Em razão dessa atividade interpretativa e dirigida à solução de problemas práticos submetidos aos pontífices, por meio de consultas formuladas por cidadãos e magistrados, vai tomando forma todo um repertório de saberes de índole normativa que constituirá a versão arcaica do direito romano. Apesar de a inovação vir sempre na forma de uma descoberta daquelas particulares exigências que os mores tinham em si involucradas, a interpretatio pontifícia contribui então criativamente para a formação daquele que seria o ius tipicamente romano, e pode ser considerada uma das suas primeiras e mais importantes fontes (BRAGA DA CRUZ, 1979, p. 147-148).

Não demoraria, contudo, até que o monopólio exercido pelo colégio dos pontífices sobre o acervo normativo da civitas, com o seu modo tipicamente aristocrático de revelação do ius, baseado num responsum de tipo oracular, fosse desafiado pelo "modelo da lei” (SCHIAVONE, 2005, p. 74 e ss.). No século V a. C., Roma sentirá de fato as reivindicações da plebe por uma lei escrita e por um regime de igualdade sub lege, inspirado nas leis de Sólon. Uma comissão é enviada à Grécia a fim de estudar o modelo legal grego, a seguir é instituída uma comissão para redigir as leis romanas, e tudo resulta em meados do século na Lex duodecim Tabularum (CRUZ, 1984, p. 178-179). É nessa etapa da história romana que se confrontam pela primeira vez o modelo político da lex e o paradigma sapiencial do ius. 
Embora a fase clássica do desenvolvimento da iurisprudentia e de um ius destacado da sua matriz religiosa não tivesse nem sequer iniciado, o modelo da lei se deparou em Roma com uma experiência alternativa já suficientemente consistente e capaz de se afirmar contra o paradigma legal expressivo da proeminência da política, típica da atitude grega. Foi sem dúvida neste momento da história que o "povo do direito" (SCHULZ, 2000, p. 205) demarcou a linha que viria a separá-lo de uma civilização para a qual o ius nem nome tinha, devido à pura e simples "mancanza della cosa" (SCHIAVONE, 2005, p. 78).

Paradoxalmente, a Lei das XII Tábuas foi o primeiro passo (BRAGA DA CRUZ, 1979, p. 142-143) de um processo de laicização que culminaria na fase clássica do desenvolvimento da iurisprudentia, quando então o paradigma romano do ius viria finalmente à luz em todo o seu esplendor, revelando, ademais, toda a sua pontencialidade. Num primeiro momento, a carga normativa da legislação romana se viu totalmente absorvida pelo "saber secreto" dos pontífices (KUNKEL, 1999, p. 106). De fato, as XII Tábuas exprimiam um saber extratificado e já muito elaborado ${ }^{2}$, que, por isso, demandava para sua elucidação e prática aplicação uma intervenção do colégio dos pontífices. $\mathrm{O}$ trabalho exegético dos sacerdotes voltava assim a se manifestar na forma das responsa, com o que aqueles acabaram por se apropriar da lei, encerrando-a na trama explicativa e adaptadora das próprias pronúncias. Desse modo, a novidade acabou por ser reabsorvida, esterilizada e integrada à prática pontifícia, de forma que, entre lex e responsum, esta expressão da iurisprudentia pontifícia voltaria a prevalecer na formação do ius, permanecendo, assim, por séculos. E foi dessa maneira que se consolidou um dos traços essenciais de toda romanidade: o primado do saber dos experts relativamente às normas provenientes das instituições políticas da cidade, e o isolamento do ius num conjunto de práticas subtraídas ao domínio direto das instâncias políticas (SCHIAVONE, 2005, p. 9193).

Mas um ulterior passo teria ainda de ser dado para que a iurisprudentia romana assumisse, derradeiramente, todas as suas distintivas características. Faltava, a saber, completar o processo de laicização, e isto só sucedeu quando, a partir do séc. III a. C., as responsa passaram a ser oferecidas aos consulentes perante todos que quisessem se instruir nas coisas em que, até então, eram versados apenas os pontífices. O "segredo" em torno do conhecimento especificamente jurídico viria a ser assim superado, e os pontífices

\footnotetext{
${ }^{2}$ A Lei das XII Tábuas era ainda lex, afinal, no sentido pré-moderno do termo: "the public and authoritative declaration of what was ius" (STEIN, 1999, p. 4).
} 
passariam a enfrentar a concorrência de todos que pretendessem se dedicar ao cultivo do ius. Forma-se, então, uma classe de experts que se distinguirá por um saber laico voltado à solução de problemas práticos concernentes às relações entre os cidadãos. Só a partir daí o monopólio do colégio pontifício será realmente quebrado, e serão inteiramente diferenciados dos pontífices e do seu compreensivo saber uma classe de jurisconsultos - os iuris prudentes -, e um saber prático autônomo que merecerá ser chamado iurisprudentia, no sentido próprio do termo (BRAGA DA CRUZ, 1979, p. 146-147; KUNKEL, 1999, p. 106). Vemos, então, como a escolha, pelos romanos, do paradigma do ius, e a entrada em cena do jurista, determinaram o nascimento do direito como uma dimensão autônoma do complexo normativo socialmente relevante (SCHIAVONE, 2005, p. 96-97).

\section{0 jurisconsulto}

Não é possível compreender a especificidade desse direito senão por referência ao jurista e à sua atividade. Numa formulação representativa de um consenso entre os romanistas, pode-se dizer que os juristas foram os "protagonisti assoluti della civiltà giuridica romana" (SCHIAVONE, 2005, p. 30). A sua era uma profissão apenas em sentido impróprio, uma "profissão aristocrática", pois a dedicação dos juristas romanos ao direito não tinha nenhum fim econômico imediato nem estava diretamente relacionada ao exercício de um ofício, e vinha exclusivamente apoiada numa auctoritas que, diversamente da autoridade moderna, era expressão não do poder, mas de um reconhecimento social espontâneo dependente da virtude, do prestígio, da competência e do talento (BRETONE, 2004, p. 153 e ss.). É por sua autorevolezza, naquele particular sentido, que os juristas eram procurados para responder quesitos relativos aos problemas práticos emergentes da complexa dinâmica das relações entre os cidadãos (LOMBARDI, 1967, p. 35-36 e 68).

Como antes os pontífices, os jurisconsultos romanos exerciam um elevado sacerdócio - eram, conforme Ulpiano, os sacerdotes da justiça (D. 1, 1, 1, 1), assim considerados por sua prudentia, donde serem chamados os prudentes, "aqueles que sabem agir" (CRUZ, 1984, p. 56-57 e 289). Com uma nota distintiva, porém: o seu sacerdócio é agora derivado de um específico e laico saber prático; não de uma prudentia no mais amplo significado da expressão, mas de uma particular iuris-prudentia. A palavra incorporada pelo jurista nas suas responsa é a palavra daquele que sabe (LOMBARDI, 1967, p. 18), mas o seu é um saber especializado e veiculado por um modo muito 
específico, para a solução de um tipo também específico de problemas (BRETONE, 2004, p. 161-162). Convém então voltarmo-nos à atividade jurídica desses jurisconsultos, para que sobressaia com maior clareza a natureza daquele saber e do direito que este saber parcialmente incorpora e dele parcialmente resulta.

\section{A praxis jurídica e o desenvolvimento de um direito jurisprudencial}

Em primeiro lugar, é importante destacar o caráter eminentemente privado, ou pelo menos não oficial, da atividade dos juristas romanos. Mesmo que o jurista porventura ocupasse algum ofício, enquanto jurisconsulto a sua atuação se conservava privada e autônoma relativamente às suas eventuais atividades públicas (BRETONE, 2004, p. 159; LOMBARDI, 1967, p. 16-17; SCHIAVONE, 2005, p. 30; KUNKEL, 1999, p. 121). Mesmo assim, as suas responsa tinham valor normativo, pois vinham suportadas pela sua auctoritas. Com efeito, embora a auctoritas fosse uma expressão do prestígio social e tivesse o seu suporte no reconhecimento de certas qualidades pessoais - e não, conforme sublinhamos, um vínculo de sujeição, baseado na heterônoma imposição de uma potestas , trata-se de uma qualidade normativa ou de um atributo dotado de relevante eficácia normativa (SCHULZ, 2000, p. 187-188).

Se um romano se destacasse no cultivo do direito, poderia esperar que as suas opiniões fossem acolhidas e observadas, por expressarem exigências de índole autenticamente normativa. E é este, na verdade, um dos motivos pelos quais muitos romanos da mais elevada estatura se dedicavam ao direito. O romano era atraído pelo direito em razão da fama, da honra, do prestígio e da popularidade que a perícia ad respondendum proporcionava (BRAGA DA CRUZ, 1979, p. 157; KUNKEL, 1999, p. 107). Se, porventura, se destacasse na tarefa, certamente colheria abundantes frutos. Notese, contudo, que a auctoritas não era independente da demonstração, pelo jurista, das suas qualidades de jurisconsulto. O valor normativo das responsa lastreava-se na sua auctoritas, mas esta não era conquistada senão pela demonstração, por parte do jurista, da sua proficiência nos assuntos do direito. Em última instância, o valor normativo das responsa radicava em um específico saber. Só assim poderia uma atividade privada assumir a primazia na formação do patrimônio jurídico da civilização do direito.

Apesar do seu valor normativo, decorrente do saber que continham, as responsa não eram diretamente orientadas à criação de regras. A vocação do jurista romano é para a 
solução justa do caso. É a isso que ele se dedica, e é nisso que é inigualável (KUNKEL, 1999, 119). O responso é o modo habitual do seu casuístico proceder. É assim, respondendo, que o jurisconsulto resolve os quesitos jurídicos que lhe são apresentados e orienta o comportamento negocial e processual dos cidadãos, as escolhas normativas dos magistrados - manifestadas nos seus editos ou nas fórmulas que orientam a solução dos casos -, e as decisões dos juízes (BRETONE, 2004, p. 195). No desempenho dessa tarefa, nem pressupunha o jurista um sistema de regras a aplicar, nem o seu direto propósito era o de criar qualquer regra. Isto não significa, contudo, que o jurisconsulto carecia de referenciais normativos, assim como não quer dizer que o valor normativo dos seus pareceres era circunscrito ao caso. Pelo contrário, ao resolver um quesito o jurista fazia avançar um direito que já existia, e assim contribuía para o seu desenvolvimento. Vejamos, então, em que termos o jurisconsulto era orientado por um corpus iuris anterior, ao mesmo tempo em que colaborava para a formação do ius romanum.

O tradicionalismo do homem romano é geralmente reconhecido, e este seu traço teve um papel decisivo na formação do direito romano (SCHULZ, 2000, p. 107 e ss.). O típico jurisconsulto nunca encara o direito em termos prospectivos, como se fosse uma tarefa só sua, ou algo inteiramente por fazer. Antes dele, já os pontífices conservavam, de geração em geração, a memória das respostas com que iam solucionando os problemas concretos submetidos à consideração do colégio pontifício, e toda nova questão era confrontada com uma massa aluvional e sedimentada composta pelo complexo das responsa anteriores, na busca de precedentes capazes de orientarem a solução exigida pelo caso. Quando se deparavam com um problema novo, os pontífices podiam, então, buscar critérios num acervo de saber prático enriquecido pela experiência e guardado pela memória. Essa prática constituiu uma longa e complexa cadeia de sucessivas responsa, e formou um primeiro saber autenticamente jurídico (SCHIAVONE, 2005, p. 67-69). Quando mais tarde o jurisconsulto assumiu a tarefa, tinha já detrás de si onde buscar orientação, e invariavelmente buscava. Segundo Lombardi, a resposta para o quesito atual era antes de tudo procurada no corpus já existente de um direito jurisprudencial, e isto a ponto de a atividade do jurista poder vir descrita como "un [contínuo] responso sui responsi”" (LOMBARDI, 1967, p. 27-28 e 66).

Isso não significa que o jurista romano reproduzia apenas ou aplicava mecanicamente um direito pressuposto. Se aquele ininterrupto diálogo com o passado assegurava a continuidade de um processo formativo em cadeia (SCHIAVONE, 2005, p. 
159), a permanente abertura para o problema e para a problemática da sua adequada solução permitia que o saber jurídico andasse num contínuo crescer. É verdade que o jurisconsulto romano normalmente considera o caso tal como narrado, sem se preocupar com a veracidade da narrativa (SCHULZ, 2000, p. 52-53; BRAGA DA CRUZ, 1979, p. 198). Mas, mesmo que o caso seja apreciado in statu assertionis, as questões apresentadas ao jurisconsulto são aquelas que assim este caso suscita, e procuram, no seu autorizado parecer, uma resposta adequada à solução do caso narrado. A atenção do jurisconsulto estava centrada, portanto, neste imediato propósito de prover uma solução aderente ao caso, e a prioridade desta perspectiva casuístico-problemática é geralmente exaltada, tendo sido sintetizada por Schulz quando escreveu que, para os romanos, no princípio estava o caso (SCHULZ, 2000, p. 61).

Essa metodológica priorização do caso, e a imediata preocupação com a adequação prático-normativa da solução proposta, não admitiam que o jurisconsulto se limitasse, nas diversas circunstâncias, a replicar aproblematicamente as responsa porventura dadas a casos precedentes. Os romanos sabiam melhor do que ninguém que cada caso é único e que uma adequada solução geralmente não resulta de uma operação lógica, em que as soluções precedentes venham assumidas como premissas para uma dedução. E, de fato, o acervo de critérios que a tradição transmitia era visto pelo jurista como um complexo de aquisições casuísticas de uma experiência passada que teria de ser no caso considerada e doravante continuada, mas não como um sistema acabado de critérios abstratos desvinculados de qualquer experiência judicativa subjacente e dotados de um sentido normativo geral que permitisse uma pura aplicação, à maneira proposta pela teoria da subsunção.

É evidente que o jurisconsulto romano encontrava regras quando buscava critérios para a solução do caso novo. Mas ele tinha bem presente que as regulae porventura identificáveis no contexto de uma praxis jurídica como a romana não passavam de simples expressões já generalizadas das soluções dadas aos casos anteriores, de maneira que só adquiririam valor para o caso atual se, num confronto de natureza analógica, resultasse da comparação dos casos a conclusão de que, por sua similaridade, o novo merecia uma solução análoga ou mesmo idêntica à do anterior.

Uma lúcida percepção da dinâmica deste modo de formação do direito recomendava sempre uma atenta consideração das soluções precedentes, mas também abria ao jurisconsulto a via para a compreensão de que as regras não podem ser 
consideradas fontes autônomas do conhecimento do direito, nem critérios suficientes para a solução dos casos novos, na medida em que apenas refletem um direito forjado pela casuística e expressivo das soluções dos casos anteriores, podendo ocorrer, portanto, de este direito formado pela jurisprudência e involucrado nas soluções precedentes já não ser o direito exigido pelas circunstâncias do caso atual (KASER, 1962, p. 111 e 115). Daí a resistência romana à abstração, e o ceticismo do jurisconsulto no que concerne ao valor prático-normativo das regras (KASER, 1962, p. 111; SCHULZ, 2000, p. 62-63; STEIN, 1995, p. 105-106).

Em vez de partir de um sistema de regras para aplicá-las ao caso, o jurisconsulto parte do caso em busca de argumentos que orientem a sua solução (KASER, 1962, p. 114115). Se nesta busca encontra regras, ele as confronta problematicamente com o caso, para verificar se oferecem uma adequada resposta. As regras são assim testadas porque a prioridade é do caso e o propósito do proceder é a justeza da solução, e não a manutenção da estabilidade de um sistema normativo de regras dotadas, cada uma, de um significado constante e de um inalterável âmbito e modo de aplicabilidade. Isto justifica que Viehweg tenha atribuído natureza tópica ao método dos jurisconsultos (1986, p. 73 e ss.), embora talvez não seja irrelevante o reparo que lhe fez Kaser, para notar que apenas em uma minoria de casos os juristas romanos encontravam os argumentos de que precisavam em regras e noções gerais que pudessem ser, neste sentido, qualificadas como topoi. Frequentemente, os jurisconsultos encontravam as soluções de que precisavam nas circunstâncias mesmas do problema ou na solução de um caso vizinho que ainda não dera lugar a uma regra de índole geral (KASER, 1962, p. 114). Seja como for, é certo que os critérios disponíveis, constituindo ou não autênticos topoi, não operavam como premissas tiradas de um sistema pressuposto. A memória de casos análogos e precedentes jurisprudenciais intervinha numa consideração problemática das alternativas soluções porventura apropriadas ao caso, e frequentemente, este confronto entre possibilidades judicativas diversas dava lugar à polêmica, num diálogo entre opiniões que as fontes denominavam disputatio (BRAGA DA CRUZ, 1979, p. 176; BRETONE, 2004, p. 200).

É evidente que de um proceder desse tipo não pode resultar uma pura reprodução de um direito pressuposto. Na praxis dos jurisconsultos, o direito ia se desenvolvendo e aperfeiçoando, para adaptar-se às exigências de cada caso, e por isso o iuris prudens, colocando-se embora na posição de intérprete, acabava por ser também o principal artífice do ius civile (JUSTO, 2003, p. 86; BRETONE, 2004, p. 161-162). É certo que o direito era 
procurado num corpus iuris já existente, mas também que o desenvolvimento daquele mesmo corpus vinha garantido pelo pensamento problemático de uma militia respondendi (LOMBARDI, 1967, p. 32). Sempre orientado pela tradição e por um saber acumulado, movendo-se dentro do marco de um corpus iuris anterior, o jurisconsulto se sentia à vontade para propor os ajustes e desenvolvimentos que os casos exigissem, num proceder que era ao mesmo tempo, portanto, cumulativo e seletivo, tradicionalista e experimental, inventivo mas resistente ao radicalismo crítico, criativo mas infenso ao reformismo. Tudo a permitir uma progressão cuidadosa, sem rupturas, em um contínuo crescimento (BRETONE, 2004, p. 199 e 294; SCHULZ, 2000, p. 38 e 107 e ss.).

É claro que dessa contínua praxis resultam regras. Mas as regras que assim emergem são aquelas generalizações sempre precárias que resultam de uma problemática atividade judicativa centrada no caso, e que, portanto, nunca chegam a se imobilizar num sistema acabado de critérios abstratos. Este ponto é decisivo e marca um dos traços distintivos de toda experiência jurídica pré-moderna. Conforme ao modo romano de ver as coisas, direito é não aquilo que o jurista encontra pronto em uma regra, mas o que ele procura para solucionar um caso. O ius é, sobretudo, aquele específico critério que, caso a caso, se encontra, para desatar os nós da vida concreta, e que só de caso em caso, cautelosamente, vai admitindo generalização; se assim vão se formando regras, é certo que isto se passa na forma de uma acumulação devida à memória dos juristas, que de caso em caso vão colhendo e preservando as aquisições, numa renovação que sucede só gradualmente e conforme às exigências dos problemas concretos (LOMBARDI, 1967, p. 19/20).

Esse casuístico modo de formação de regras foi explicado por Kaser no seu ensaio sobre o método dos jurisconsultos romanos. Referimo-nos já às suas constatações para mostrar que a regra não era considerada uma fonte autônoma do ius, mas queremos ainda salientar que a premissa desta concepção, e daquela dinâmica formativa de regras, é a compreensão de que o ius não decorre da regra, mas antes o oposto: a regra é apenas uma manifestação normativa do ius - conforme Paulo, non ex regula ius sumatur, sed ex iure quod est regula fiat (D. 50, 17, 1) (KASER, 1962, p. 111). As regulae de um direito assim formado são enunciações abreviadas das aquisições de uma praxis judicativa de índole casuística. Conforme sintetizou Barzotto, o recurso à regra "nada mais é do que o recurso às soluções, comprovadas pela experiência, de uma série de casos" (1999, p. 185). O jurista romano maneja regras como quem perscruta o passado de uma experiência vivenciada, e, 
se as respeita e considera, é por seu conteúdo judicioso, e não por seu caráter imperativo (KASER, 1962, p. 120). O direito vai, então, se cristalizando em termos gerais porque certos critérios e soluções sobrevivem ao teste de uma praxis orientada à investigação casuística do ius. E é assim que se forma o ius civile, um complexo de opiniões, regras e critérios consagrados pela iurisprudentia na forma do responso e submetidos a uma contínua prova judicativa (BRETONE, 2004, p. 196-197), compondo a ossatura prescritiva das relações entre os cidadãos (SCHIAVONE, 2005, p. 104).

\section{A iurisprudentia e o ius honorarium}

Sabemos que também a atividade dos magistrados desempenhou um importante papel na formação do direito romano clássico, sendo a responsável pelo ius honorarium. O privilegiado modo de formação deste direito jurisdicional, também chamado ius praetorium, era o edito do pretor. Anualmente, os pretores faziam publicar, por meio do edictum um conjunto de fórmulas representativas dos meios processuais postos à disposição dos cidadãos para a tutela dos seus interesses, nas circunstâncias que hipoteticamente estabeleciam ${ }^{3}$. Essas fórmulas não eram, porém, desligadas da atividade jurisdicional do pretor no processo formular. No processo per formulas, o pretor atuava apenas na primeira fase do procedimento (in iure), que terminava com uma litiscontestatio representativa da aceitação pelas partes de uma fórmula, que nomeava um juiz privado e estabelecia o critério de decisão a ser observado pelo iudex na fase seguinte (apud iudicem). Esta segunda fase tinha função instrutória e culminava numa decisão conforme ao critério da fórmula e à prova produzida. A fórmula era então o modo do iudicium dare, e representava o reconhecimento, pelo pretor, de que o autor podia agir contra o demandado conforme à sua postulação, dependendo a sorte do litígio do que viesse a ser provado perante o iudex (GROSSO, 1965, p. 282; DE MARTINO, 1937, p. 193-194).

Por meio dessa atividade de índole jurisdicional, os pretores iam enriquecendo o rol de interesses que mereciam tutela, e especificando sob que condições determinadas pretensões viriam protegidas pelo ius dicere do magistrado. Ocorre que tanto as partes quanto os jurisconsultos tinham um papel decisivo neste desenvolvimento, as primeiras ao

\footnotetext{
${ }^{3}$ A fórmula continha dois períodos hipotéticos e estabelecia as condições de fato sob as quais o réu deveria ser condenado ou absolvido. Sua típica estrutura era: "Si paret... condemnato, si non paret absolvito" (ARANGIO-RUIZ, 1998, p. 124). A fórmula manifestava, portanto, o reconhecimento jurisdicional de que as hipotéticas condições que impunham a condenação conferiam ao autor, caso comprovadas, uma pretensão contra o réu (PUGLIESE, 1939, passim).
} 
proporem fórmulas e impugnarem as propostas da parte adversária, e os últimos ao orientarem as partes, e também os próprios pretores, a respeito das fórmulas a serem propostas e concedidas. $\mathrm{O}$ edito do pretor era o resultado dessa dinâmica processual que contava com a colaboração do jurisconsulto. E como também a seleção e elaboração das fórmulas que viriam a compor o edito eram orientadas pelos juristas, pode-se dizer que a formação do ius honorarium deve-se mais às responsa dos jurisconsultos e à iniciativa jurisprudencialmente orientada das partes do que ao gênio criativo do próprio pretor (BRAGA DA CRUZ, 1979, p. 166 e 171) ${ }^{4}$.

O jurista romano é também, com efeito, um "manipulador de fórmulas", e o seu contributo para o desenvolvimento do ius honorarium é decisivo. A estabilização dos critérios que vão sendo incorporados aos editos dos pretores depende da relevância que tais critérios vão assumindo na praxis jurisdicional. Mas a apuração desta relevância é confiada à iurisprudentia (BRETONE, 2004, p. 171-172 e 188 e ss.). Segundo Braga da Cruz, o êxito que o edito alcançou como fonte do direito foi proporcionado pela contínua fusão de disposições translatícias que preservavam e renovavam critérios editais anteriores (edictum translaticium), e disposições novas que incorporavam ao ius honorarium as modificações e acréscimos que a prática ia aconselhando (edicta nova), sempre conforme à orientação dos jurisconsultos (1979, p. 166). Tal como salientam os romanistas, é de fato só mediante o aporte crítico e técnico dos jurisconsultos que o ius honorarium vai se modificando e aperfeiçoando até compor, com a relevância que alcançou, ao lado do ius civile, o que hoje consideramos a porção clássica do direito romano: um direito jurisprudencial de casos e de ações, numa síntese dos aportes da iuris prudentia e da iuris dictio (SCHIAVONE, 2005, p. 117 e ss.; LOMBARDI, 1967, p. 15).

\section{A iurisprudentia e a lex}

Certamente, a lex teve a sua participação no desenvolvimento do direito romano. Mas foi uma participação bastante modesta, ainda mais quando circunscrevemos a análise ao direito privado e processual, ou seja, àquela porção do ius que forma o direito romano clássico. Isso é geralmente reconhecido pelos estudiosos do direito romano, que a propósito não cansam de salientar como a lei era extraordinária, e complementar ou

\footnotetext{
${ }^{4}$ Lembre-se que os pretores sequer precisavam ser juristas, pois contavam com a orientação de um consilium de jurisconsultos (SCHULZ, 2000, p. 261).
} 
subsidiário o seu papel relativamente a um corpus iuris que a precedia; como aparecia por todo o prolongado desenvolvimento do direito romano apenas casual e episodicamente, e, normalmente, apenas para contribuir com retoques e exceções destinadas à incorporação a um acervo normativo independente de toda intervenção legislativa (BRETONE, 2004, p. 182 e 309; LOMBARDI, 1967, p. 12-13 e 26). O "povo do direito", assevera Schulz, não é o povo da lei (2000, p. 28). Além disso, os juristas romanos também desempenhavam um papel importante na elaboração das leis (KUNKEL, 1999, p. 133), e aquelas leges que porventura invadissem o campo natural do ius civile eram, uma vez vigentes, apropriadas pelos juristas e integradas à tradição do seu saber (SCHIAVONE, 2005, p. 117), não servindo jamais, porém, como critério suficiente e autônomo para a solução de problemas jurídicos (LOMBARDI, 1967, p. 26 e 67).

Percebe-se, então, que o fator decisivo na formação e desenvolvimento do direito romano é a iurisprudentia (KUNKEL, 1999, p. 132; BRETONE, 2004, p. 184). Segundo Lombardi, as disposições editalícias do ius honorarium formavam como que uma rede de estradas circundada por toda uma paisagem composta pela iurisprudentia (1967, p. 26), e parece-nos agora que o mesmo pode ser dito em relação à lei, com a ressalva, porém, de que esta tem uma participação ainda mais modesta do que o direito dos pretores na formação daquele corpus.

\section{O ius romano e a ordem da civitas}

É claro que um direito complexo e desenvolvido ao longo de séculos, como foi o caso do direito romano, teria, forçosamente, de contar em seu desenvolvimento com os mais variados contributos, e ir se extratificando a ponto de podermos diferenciar o individual aporte das responsa dos jurisconsultos, das fórmulas e dos editos dos magistrados, assim como da legislação. Mas na dinâmica para a qual concorrem esses vários elementos intervém, continuamente, um elemento integrador e ordenador, com vistas à solução dos problemas que vão surgindo, e isto a ponto de aqueles diversos extratos virem todos absorvidos num direito que transcende cada uma das suas partes. Aquele elemento integrador e ordenador é a iurisprudentia (SCHIAVONE, 2005, p. 29).

$\mathrm{O}$ responso, orientado à adequada solução do caso, hierarquiza continuamente os diversos critérios disponíveis, especifica-lhes o sentido e apura a respectiva relevância judicativa, estende e reduz a sua aplicabilidade conforme à justeza das soluções que 
viabilizam em cada circunstância, etc., e vai assim construindo a unidade de um ius que se situa para além de cada uma das suas manifestações, quer apareçam, aqui e ali, sob a forma de responsa, formulae ou leges. É assim que se pode dizer, com Lombardi, mas em rigorosa concordância com os estudiosos em geral, que aquele ius integrante das suas várias manifestações normativas é confiado ao jurista (1967, p. 33). Trata-se, quanto ao seu modo formativo, de um Juristenrecht no sentido rigoroso do termo, pois se o edito e a lei deixaram a sua contribuição, tudo passa afinal por uma espécie de fusão que, na época pósclássica, daria lugar à consideração de toda a matéria transmitida desde a fase clássica como um unitário e autônomo ius de índole e origem jurisprudencial que viria então a ser contraposto às leges imperiais da época tardia (KUNKEL, 1999, p. 133-134; BRAGA DA CRUZ, 1979, p. 248-249).

É assim chegado o momento de perguntarmos o que é, afinal, esse direito romano. Uma conveniente resposta seria: é um conjunto de regras e critérios criados pelos juristas no contexto de uma praxis jurisprudencial casuística. Parece-nos, contudo, que devemos levar a sério a perspectiva do próprio jurista romano e os pressupostos que orientam a sua atividade. E aquela é, aparentemente, a de alguém que descobre em vez de criar, enquanto um ao menos dos pressupostos que governam toda a experiência jurídica romana é a de que o direito é mais um alvo do saber do que um artifício da vontade. Na famosa definição de Ulpiano, colhida do Digesto 1, 1, 10, 2, iuris prudentia é a ciência do justo e do injusto («Iuris prudentia est divinarum atque humanarum rerum notitia, iusti atque iniusti scientia»). É, porém, inegável que a iurisprudentia constituía uma força criativa, e os próprios romanos o reconheciam, quando caracterizavam o ius civile como aquilo que sem ter sido escrito vem composto pelos prudentes (quod sine scripto venit compositum a prudentibus), e arrolavam entre as fontes do ius civile a autoridade dos prudentes (auctoritate prudentium) e as suas respostas (responsa prudentium) (Pompônio, D. 1, 2, 2 , 5; Papiniano, D. 1, 1, 7, pr.; Ulpiano, D. 1, 1, 2, 3).

Para que essas duas constatações - de um direito que é, ao mesmo tempo, objeto do saber dos juristas e criação sua - venham equacionadas, temos que distinguir duas diferentes acepções do romano ius: como norma ou ordenamento jurídico, e como aquilo que é justo, a própria coisa justa, a realidade justa ou simplesmente o iustum ${ }^{5}$. E assim as coisas parecem se esclarecer, pois o jurista romano descobre caso a caso o ius-iustum, e do

\footnotetext{
${ }^{5}$ Sebastião Cruz designa estes dois, respectivamene, os sentidos normativo e objetivo de ius (1984, p. $20 \mathrm{e}$ ss.).
} 
saber daquilo que é justo vão num crescer resultando normas e critérios - cada um, um iusnorma - que doravante orientarão a busca casuística do ius-iustum, e que acabam por constituir um ius-ordenamento. O iustum é descoberto, não criado, mas as normas e critérios que o jurista vai continuamente formulando para expressar e de algum modo preservar o saber do iustum são autenticamente criados, ou criado ao menos é o ordenamento que resulta da composição num todo daquelas normas e critérios expressivos do conhecimento do iustum. Em suma, o ius-iustum é o objeto do saber, enquanto o iusordenamento é uma expressão daquele saber, ao mesmo tempo em que uma criação por meio da qual o jurista tenta expressar e transmitir as aquisições daquele saber.

Essa concepção de um ius-iustum descoberto parece vir confirmada pela maneira como os romanos se referiam aos juristas e ao saber que os distinguia. O jurisconsulto é o prudens, quem vê as coisas no seu aspecto valorativo conforme à verdade, como o phrónimos aristotélico. A sua específica qualidade é uma particular prudentia, aquela recta ratio agibilium orientada a desvendar o que é justo e a mover o agere conforme a este conhecimento, pelo que vai chamada "iuris-prudentia" - o distintivo atributo de quem sabe o que é justo ou injusto e como praticamente alcançar o justo e evitar o injusto. Nesse saber vai por sua vez pressuposta uma certa notitia de coisas divinas e humanas (divinarum atque humanarum rerum notitia) que de algum modo informam a ordem social e concorrem para a determinação do que é justo e injusto (CRUZ, 1984, p. 280 e ss.; JUSTO, 2003, p. 87). A iurisprudentia tem assim, também, o sentido de um conhecimento das exigências da ordem para o caso, do justo concreto conforme à natureza das coisas e das relações que a vida cria (BARZOTTO, 1999, p. 179-180 e 186/187; SCHULZ, 2000, p. 55). Mesmo que o direito romano seja, então, criado pelos jurisconsultos, é certo que isto se passa sobre a base de uma "prática cognitiva" (SCHIAVONE, 2005, p. 104-105) que dá suporte àquele direito, por fazer dele a expressão de um saber prático-prudencial acerca do justo, da própria res iusta. E se, portanto, a iurisprudentia, as responsa ou a auctoritas dos juristas constituem em conjunto a principal fonte do direito romano, é, primeiramente, no sentido muito específico de "lugar onde nos aparece o direito", no sentido "objetivo" do termo (CRUZ, 1984, p. 162-163). O direito romano é o direito tal como aparece aos juristas romanos na sua busca inquisitiva e casuística do justo concreto; é o direito tal como conhecido pelos juristas romanos, e é neste sentido que a iurisprudentia é fonte autônoma e por excelência daquele direito (LOMBARDI, 1967, p. 61 e ss.).

A perspectiva em que o direito assim aparece é aquela na qual prevalece a procura, 
nas coisas, do justo, em perspectiva microscópica. O que importa ao jurista romano é o que é justo no caso, considerando a ordem das relações humanas tais como se apresentam, e o lugar de cada um nessa mesma ordem. O direito como iustum aparece e como ordenamento é criado na abertura do jurista para o problema do justo concreto. Nesta inquisição do justo concreto a praxis jurídica se abre para uma ordem de validade que não é, a rigor, criada, e que transcende a ordem da sociedade, pois o justo buscado pelo jurista não é uma simples invenção daquela mesma sociedade. Quando a sociedade, porém, incorpora normativamente o saber assim adquirido, aquela validade permeia a ordem da sociedade, e a tradução daquele saber na forma de um ordenamento jurídico equivale à incorporação, pela ordem da sociedade, de uma validade transcendente. $\mathrm{O}$ direito constitui-se, assim, como uma ordem de validade que orienta normativamente a praxis, na medida em que é expressiva de um saber relativo ao justo.

Não sabemos ao certo se essa nossa interpretação apreende adequadamente o pensamento dos juristas romanos, mas parece-nos, de qualquer forma, que se ajusta à sua própria perspectiva. Seja como for, queremos retê-la, pois vemos aí uma das chaves para a compreensão da juridicidade. Essa ordem histórica de validade que se forma em abertura para uma validade transcendente simbolizada pelo justo constitui, na experiência romana, um direito autônomo expressivo de um saber jurisprudencial e composto por um longo processo de densificação prudencial de critérios normativos em que aquele saber se revela e por meio dos quais se transmite. E como aquela ordem jurídica histórica e a ordem de validade simbolizada pelo iustum se comunicam numa articulação sempre imperfeita e incompleta, jamais o direito romano se imobiliza num fechado sistema de regras, como se a tensão entre o que é justo e o que o direito romano prescreve em cada passo da sua história pudesse vir definitivamente superada. O que temos então é um direito sempre em formação mas em contínuo vínculo com o passado, compondo um repositório ou depósito de opiniões e pareceres, regras, dados normativos, definições e conceitos, esquemas negociais e fórmulas processuais que vão se acumulando e são constantemente manipulados e postos à prova pela razão jurídica, na busca sempre precária, mas também firmemente orientada, de uma solução justa para os casos que vão sendo continuamente submetidos aos juristas (BRETONE, 2004, p. 309-310).

A tensão que assim reiteradamente aparece, entre um corpus iuris resultante da experiência anterior e as demandas que os casos novos apresentam, é o problema específico do jurista, e, do seu esforço para mediar aquele corpus e a exigência de uma 
justa solução para cada caso novo, emerge uma ordem de validade normativa de superfície fluida, cujo movimento nunca cessa (SCHIAVONE, 2005, p. 37). Os juristas são os custodes de um tal direito, e a sua autoridade é reconhecida em razão do saber que faz deles os "arquivos vivos do direito" (LOMBARDI, 1967, p. 20), com a importante ressalva de que este ius custodeado pelos juristas incorpora um saber comunitário que transcende o saber individual e excede o contributo de cada um deles, superando, ademais, a capacidade de qualquer legislador (KUNKEL, 1999, p. 119; LOMBARDI, 1967, p. 76; SCHULZ, 2000, p. 109), além de não poder ser reduzido a nenhuma das suas específicas manifestações, vez que forma uma ordem de validade perante a qual todos os possíveis novos critérios vão sendo judicativamente testados, e na qual vão sendo assimilados ou introduzidos quando e conforme enriqueçam aquele acervo normativo, e não por conta da origem que apresentem - um ius que portanto não tem "fonte" no sentido moderno do termo, a saber, um lugar de onde o que quer que proceda será, só por isso, direito.

E este é um direito rigorosamente autônomo, quanto ao seu modo de formação e quanto à sua intencionalidade, pois é forjado por um saber especificamente jurídico no contexto de uma prática jurisdicional intencionada casuisticamente ao iustum concreto, que é o objeto próprio daquele saber e a razão de ser daquela praxis. A perspectiva de um tal autônomo ius é sempre a de uma certa justiça microscópica, para a qual não importam intenções propriamente políticas - com a sua peculiar tendência a ver as coisas e o problema da justiça desde a perspectiva da sociedade como um todo ou do bem comum -, mas, diversamente, o equilíbrio comutativo entre posições individuais (LOMBARDI, 1967, p. 12-14, 28 e 29-30). A ordem que forma é como uma linguagem que, ao longo do tempo, se desenvolve lenta e espontaneamente conforme à necessidade e ao aporte criativo de quem se comunica (KUNKEL, 1999, p. 119; LOMBARDI, 1967, p. 76), e não como um conjunto de imperativos que descem sobre os cidadãos desde um locus onde se situa um poder político legiferante (LOMBARDI, 1967, p. 12-13). Um direito, ademais, que se conserva autônomo porque desenvolve uma racionalidade própria encerrada em uma linguagem técnica capaz de imunizar a atividade jurídica contra o reformismo legislativo e a vontade arbitrária do poder (SCHIAVONE, 2005, p. 37-38 e 163; LOMBARDI, 1967, p. 35). E um direito que também se mantém à parte da filosofia, pela especificidade do seu objeto - o iustum - e pela praticidade da sua intenção (BRAGA DA CRUZ, 1979, p. 178179; KUNKEL, 1999, p. 109; CRUZ, 1984, p. 287-288).

O mais notável é que esse autônomo direito só se estabelece na civitas romana 
graças ao saber privado do iuris peritus (Pompônio, D. 1, 2, 2, 13) (LOMBARDI, 1967, p. 05 e ss. e 21) e ao reconhecimento espontâneo que constitui a sua auctoritas $^{6}$, mas apesar desta peculiaridade aquele ius forma o "logos da república", dando substância normativa à ordem comunitária da civilização mais pujante da história ocidental, e constituindo a trama do seu tecido social e o seu mais relevante vínculo comunitário (SCHIAVONE, 2005, p. 107-10 e 116). Paradoxalmente, isto só começa a se reverter com a tendência à apropriação político-estatal do direito. O primeiro passo dado neste sentido foi a criação, por Augusto, do ius respondendi ex autoritati principis, e a captura da iurisprudentia, que a partir daí foi lentamente se consolidando, culmina, afinal, na sua decadência, até a completa paralisia do desenvolvimento jurídico que por séculos vinha progredindo sob a custódia dos juristas (BRAGA DA CRUZ, 1979, p. 191 e ss. e 246 e ss.). Mas, apesar disso, só com a modernidade assistiremos à consolidação de um universo de concepções radicalmente incompatíveis com aquela praxis jurisprudencial que viabilizou a emergência e a afirmação histórica de um ius autônomo. Antes disso, ainda veríamos florescer no medievo uma compreensão da juridicidade e da praxis jurídica afim à romana, pois a experiência que dará lugar ao desenvolvimento do ius commune também repousa na pressuposição de que o direito é uma ordem não-estatal de validade que vai incorporando critérios na medida em que são postos judicativamente à prova pela praxis, sob a orientação dos juristas e conforme aos contributos da sua inveniendi.

\section{A experiência jurídica medieval}

Durante o medievo, a jurisprudencialidade do direito é preservada, embora o papel mais proeminente seja agora o da "doutrina" (LOMBARDI, 1967, p. 79 e ss.). Os doutores se encarregam da coordenação e organização hierárquica das fontes e dos plurais ordenamentos jurídicos, da formulação de critérios interpretativos com vistas à solução de problemas concretos conforme às várias e concorrentes manifestações da juridicidade, e também, é claro, do próprio desenvolvimento inventivo daquilo que formará o conteúdo material do ius commune. A iurisprudentia medieval funciona, portanto, como o elemento integrador capaz de fazer de um complexo de materiais jurídicos heterogêneos um direito comum aos povos europeus. Leges, rationes e auctoritates concorrem na articulação, pelo

\footnotetext{
${ }^{6}$ Segundo Santos Justo, na época republicana a auctoritas do jurista é "inequivocamente expressa na consideração dos iuris periti como principes civitatis e da sua casa como oraculum civitatis" (2003, p. 87).
} 
jurista, das suas opiniões, e tudo conflui, pelas mãos dos doutos, para a formação de um direito que transcende cada uma das suas manifestações, mas também cada um dos protagonistas desta atividade ao mesmo tempo integradora e criativa. Do ponto de vista do direito resultante dessa intervenção jurisprudencial, mesmo os textos jurídicos mais autoritativos, como o próprio Corpus Iuris, aparecem ainda como "projetos de direito" que em relevância e sentido terão de ser aquilatados e traduzidos pelos juristas para uma sua adequada integração a um ius que supera toda lex e vai escondendo os textos detrás de si, na medida em que os incorpora a um todo normativo maior. A unidade deste todo e a relativa certeza que é capaz de proporcionar vão procuradas no conjunto das opiniões dos doutores, com o propósito de verificar com fins práticos onde convergem, e quais devem prevalecer quando divergem.

A incontrastável autoridade e a relevância prático-judicativa que a communis opinio doctorum alcançará são os mais relevantes indícios da índole jurisprudencial do ius commune, e denunciam a prevalência da atitude que marca as experiências jurídicas romana e inglesa: o jurista trata o direito como um acervo de conhecimentos acumulados e procura neste repositório normativo os critérios necessários à solução dos problemas atuais, pois sabe que o direito vai ao longo do tempo incorporando as aquisições viabilizadas pelo trabalho de gerações de juristas, até constituir a expressão de um saber prático que ultrapassa o de qualquer indivíduo. O respeito à communis opinio manifestava, ao mesmo tempo, uma preocupação com a justeza ou veracidade das opiniões relevantes na medida em que o consenso dos doutores vinha compreendido como o mais seguro sinal de verossimilhança naquilo que era incerto - e com a certeza possível no domínio daquilo que é problemático por excelência - pois, na dúvida, os juristas práticos seguiam a opinião comum, com o resultado de que a communis opinio funcionava como um modo "endojurisprudencial" "7 de estabilização de normas gerais, para o enfrentamento da relativa insegurança inerente a toda experiência jurisprudencial. Esses dois pólos da justeza e da certeza dialogam e se equilibram, portanto, pela mediação dos próprios juristas, e conforme aos critérios jurisprudenciais que indicam quando a communis opinio deve prevalecer ou ceder, para que o acervo de conhecimentos jurídicos se mantenha aderente aos problemas e vá se enriquecendo num crescer que preserva as aquisições proporcionadas pela experiência anterior. E se assim vão decerto se formando regras, a

\footnotetext{
${ }^{7}$ Segundo Lombardi, a communis opinio aparece como um "fenômeno legalístico endojurisprudencial", ou seja, como o esforço de um ordenamento jurisprudencial para dar-se a própria "lei" (1967, p. 184).
} 
perspectiva é ainda a dos juristas romanos: a prioridade é do problema, de maneira que as regras são inferências obtidas a partir das soluções que a praxis vai consagrando, e não critérios estabilizados num sistema a partir do qual as soluções possam ser obtidas dedutivamente (HESPANHA, 1998, p. 122).

Vemos assim que no medievo o direito é ainda, em suma, "coisa de juristas" (LOMBARDI, 1967, p. 111). Mesmo quando se busca aquela precária certeza que apenas o respeito a normas gerais pode proporcionar, é na opinião dos juristas, e conforme aos seus próprios critérios de relevância, que toda atenção vai centrada. E assim se preserva, novamente, um direito autônomo de índole jurisprudencial, não político-estatal. Um direito que não é posto por alguém mas vai sendo forjado pelos juristas, na procura de soluções para os problemas jurídicos; cuja juridicidade não vai extraída da sua origem mas do seu conteúdo material; que incorpora mais um acervo de saberes práticos adquiridos do que um sistema de imperativos voltados a assegurar a obediência. Esse direito convive com um poder político despojado de toda vocação totalizante, que, assim, deixa fora do seu alcance potestativo todo um amplo espaço para a emergência de uma normatividade proveniente de baixo, na articulação mediada e orientada pelos juristas das relações entre particulares.

Mas o direito que assim vai se formando espontaneamente não é apenas o conteúdo de um espaço normativo residual. No medievo, o poder político se vê juridicamente subordinado a uma juridicidade não-estatal, e esta é a mais proeminente característica da "constituição" medieval. O seu material substrato é composto, em larga medida, por um ius non scriptum que encerra valores e costumes indisponíveis, subordinando à autoridade política. Um príncipe digno do ofício será, assim, não um legislador onipotente, mas um fiel custode do justo e do equitativo conforme àquele ius, e mesmo a sua lex scripta não poderá senão especificar as exigências de um antecedente ius non scriptum ou reforçar, com a autoridade política, a sua intrínseca carga normativa (GROSSI, 2007, p. 06 e ss., e 2004, p. 28 e ss.).

Na sintética formulação de Paolo Grossi, podemos, então, quanto ao medievo, dizer que "antes existia o direito; o poder político vem depois" (2004, p. 31). E um direito autônomo que, ao vir no medievo tardio apropriado e desenvolvido pelos "doutores", em permanente contato com a praxis, constituía um autêntico "diritto senza Stato" de uma inteira comunidade de juristas que não conhecia fronteiras (GROSSI, 2007, p. 52-53). Esses juristas não eram, porém, o equivalente medieval do legislador moderno, pois o direito que tinham aos seus cuidados não era uma arbitrária ou voluntarística criação sua, 
mas, diversamente, um ius involucrado na ordem das coisas que tinha, por isso, de ser nelas descoberto e pelos prudentes traduzido, em termos que lhe conferissem inteligibilidade e operacionalidade prática. Se a época do ius commune teve as suas distintivas peculiaridades, não é menos verdade que, no essencial, prolongou a experiência jurídica romana e se prendeu ao paradigma sapiencial do ius. Tudo a sugerir que estamos no tempo já perto, mas, quanto às ideias, longe ainda da modernidade.

\section{Conclusão}

O direito que herdamos da tradição e identifica a nossa civilização não é um sistema de imperativos legais impostos por instâncias políticas para o cumprimento de fins político-sociais. Sempre constituiu uma ordem espontânea de validade normativa material forjada pela razão prática com intenção ao justo concreto. Era antes um saber do que um poder. E um saber que, como tal, merece ser ainda hoje preservado e mobilizado, pois é o mais seguro indicativo do que a cada um é devido em cada contexto relacional, a despeito dos circunstanciais objetivos políticos de quem nos governa e das estratégias políticosociais da ideologia domintante.

\section{Referências}

ARANGIO-RUIZ, Vicenzo. Istituzioni di diritto romano. 14. ed. Napoli: Jovene, 1998.

BARZOTTO, Luis Fernando. Prudência e jurisprudência - Uma reflexão epistemológica sobre a jurisprudentia romana a partir de Aristóteles. Anuário do Programa de PósGraduação em Direito. Mestrado e Doutorado (UNISINOS). 1998 - 1999. São Leopoldo, 1999.

BRETONE, Mario. Storia del diritto romano. 10. ed. Roma/Bari: Laterza, 2004.

BRAGA DA CRUZ, Guilherme. O «jurisconsultus» romano. In: Obras esparsas. v. I. Coimbra: Universidade de Coimbra, 1979.

CRUZ, Sebastião. Direito romano (Ius Romanum): I Introdução. Fontes. 4. ed. Coimbra: DisLivro, 1984.

DE MARTINO, Francesco. La giurisdizione nel diritto romano. Padova: CEDAM, 1937.

GROSSI, Paolo. L'Europa del diritto. Bari: Laterza, 2007. 
GROSSI, Paolo. Mitologias jurídicas da modernidade. Tradução: Arno Dal Ri Júnior. Florianópolis: Boiteux, 2004.

GROSSO, Giuseppe. Lezioni di storia del diritto romano. 5. ed. Torino: G. Giappichelli, 1965.

HESPANHA, António Manuel. Panorama histórico da cultura jurídica europeia. 2. ed. Portugal: Europa-América, 1998.

JUSTO, Santos. Direito Privado Romano: I (Parte Geral). 2. ed. Coimbra: Coimbra Editora, 2003.

KASER, Max. Sur la méthode des jurisconsultes romains. Tradução: M. Joseph Modrzejewski. Romanitas. Rio de Janeiro, n. 5, 1962.

KUNKEL, Wolfgang. Historia del derecho romano. Tradução: Juan Miquel. Barcelona: Ariel, 1999.

LOMBARDI, Luigi. Saggio sul diritto giurisprudenziale. Milano: Giuffrè, 1967.

PUGLIESE, Giovanni. Actio e diritto subiettivo. Milano: Giuffrè, 1939.

SCHIAVONE, Aldo. Ius: L'invenzione del diritto in Occidente. Torino: Einaudi, 2005.

SCHULZ, Fritz. Principios del derecho romano. 2. ed. Tradução: Manuel Abellán Velasco. Madrid: Civitas, 2000.

STEIN, Peter. Ifondamenti del diritto europeo: Profili sostanziali e processuali dell'evoluzione dei sistemi giuridici. Tradução: Anna De Vita, Maria Donata Panforti e Vincenzo Varano. Milano: Giuffrè, 1995.

STEIN, Peter. Roman law in European history. Cambridge: Cambridge University Press, 1999.

VIEHWEG, Theodor. Tópica y jurisprudencia. Tradução: Luis Díez-Picazo. Madrid: Taurus, 1986. 